\title{
Two brothers with a symptomatic thoracic disc herniation at T11-T12: clinical report
}

\author{
Geke M. Overvliet • Emile A. M. Beuls • \\ Mariel ter Laak-Poort • Erwin M. J. Cornips
}

Received: 18 February 2009 / Accepted: 18 February 2009/Published online: 6 March 2009

(C) The Author(s) 2009. This article is published with open access at Springerlink.com

\begin{abstract}
Background In contrast to what is commonly believed, thoracic disc herniations are not rare lesions. Their etiopathogenesis is largely unknown, but may be linked to trauma, Scheuermann's disease or a degenerative back.

Objective We report two brothers with a symptomatic thoracic disc herniation at T11-T12 and address the possibility of a genetic factor as well as other factors in the etiopathogenesis of (symptomatic) thoracic disc herniations. Clinical features Both brothers were in their early thirties and had a physically demanding job, however, only the first one was a smoker and was diagnosed with Scheuermann's disease.

Conclusion The etiology of thoracic disc herniations is likely multifactorial. Their occurrence in siblings may reflect some genetic predisposition or may be merely coincidental, given the high prevalence of thoracic disc herniations in asymptomatic individuals. Further research, including genetic studies, is warranted.
\end{abstract}

Keywords Etiopathogenesis - Genetics ·

Scheuermann's disease - Thoracic disc herniation .

Thoracoscopic microdiscectomy

G. M. Overvliet • E. A. M. Beuls • M. ter Laak-Poort •

E. M. J. Cornips $(\square)$

Department of Neurosurgery,

Maastricht University Medical Center,

P. Debyelaan 25, P.O. Box 5800, 6202 AZ Maastricht,

The Netherlands

e-mail: e.cornips@mumc.nl

\begin{abstract}
Abbreviations
CT Computerized tomography

MRI Magnetic resonance imaging

$\mathrm{T}$ Thoracic
\end{abstract}

\section{Introduction}

In contrast to what is commonly believed, thoracic disc herniations are not rare lesions, with an incidence of $37 \%$ on magnetic resonance imaging (MRI) scans in asymptomatic individuals [21]. On the other hand, they are frequently overlooked by clinicians who are unaware of their diverse and often misleading clinical presentation, this can include axial, thoracic or abdominal pain syndromes, non-radicular pain in one or both legs, claudication, sensory disturbances, as well as problems with micturition and defaecation $[5,7,9,11,14,17$, 19]. Symptoms are usually slowly progressive, but may also have a more (sub)acute or even relapsing - remitting course.

Over the past 8 years we have performed thoracoscopic microdiscectomies in 180 patients referred mainly from The Netherlands and from Belgium. In this series, patient age ranged from 23 to 83 years with a mean age of 48.8 years and most patients (73\%) above 40 years. Most of the time we could not identify what triggered the onset of symptoms, although a few patients $(n=8)$ presented with pain and/or myelopathy after a car accident.

Two of our patients were brothers with a symptomatic thoracic disc herniation at $\mathrm{T} 11-\mathrm{T} 12$, who presented to our department at an age of 34 and 32 years respectively. To the best of our knowledge two siblings with a symptomatic thoracic disc herniation, let alone at the exact same level (T11-T12) and early age (both in their 
early thirties), has not been previously reported. We address the possibility of a genetic factor as well as other factors in the etiology and pathogenesis of (symptomatic) thoracic disc herniations.

\section{Clinical features}

\section{Patient 1}

The first patient was a healthy 34-year-old man, smoker, with a history of cholecystectomy, first rib resection for thoracic outlet syndrome and an ankle operation. He visited our outpatient clinic with pain in his lower back radiating to his right leg for 2 years. More recently, he had developed pain at the thoraco-lumbar junction, pain in both upper legs and knees, paresthesias under the left foot and an unstable gait. He had normal sphincter control. Because of these complaints, he was unable to do his job as a train shunter for more than a year. Neurological examination demonstrated normal strength and sensation, generalized hyporeflexia, vivid abdominal reflexes, local tenderness over the lower thoracic spine, limited anteflexion and discrete gait instability. MRI (Fig. 1a, b) demonstrated a right mediolateral disc herniation at T11-T12 with cord deformation (anterolateral flattening in the area of the spino-thalamic and anterior spino-cerebellar tracts). Obliteration of the subarachnoid space is more obvious on the axial CT (computerized tomography) image with intrathecal contrast obtained in prone position [3] (Fig. 1c). Moreover, there were radiological signs of Scheuermann's disease, as at least three adjacent thoracic vertebrae had an anterior wedging of $5^{\circ}$ or more. The hernia was successfully removed through a right-sided thoracoscopic approach with retraction of the diaphragm through an extra portal. The postoperative course was uneventful, with immediate disappearance of pain and paresthesias, and normalization of his gait pattern within a few weeks.

\section{Patient 2}

The second patient was a healthy 32-year-old man, nonsmoker, without any medical history. He visited our outpatient clinic accompanied by his brother, who actually was the patient described in case 1 . For about 1 year he had been experiencing pain at the thoraco-lumbar junction, radiating to his left leg in a non-radicular fashion. Because of frequent, heavy lifting, he was unable to perform his job in a bakery. Neurological examination demonstrated mild paresis of his left leg, no sensory loss, vivid reflexes in the lower extremities, normal plantar reflexes, and local tenderness at the thoraco-lumbar junction with paravertebral muscle spasms. His gait was unstable. Sagittal T2 (Fig. 2a(1 and 2)) and axial T2 DRIVE (Fig. 2b) MRI demonstrated a left mediolateral disc herniation at T11-T12 with severe compression of the segmental spinal cord and myelomalacia, whereas a coronal MR myelographic image confirmed a complete cerebrospinal fluid block at the involved level (Fig. 2c). In contrast to the first patient, there were no radiological signs of Scheuermann's disease. The hernia was successfully removed through a left-sided thoracoscopic approach, again with retraction of the diaphragm. The postoperative course was uneventful, with immediate pain relief.

\section{Discussion}

The etiopathogenesis of thoracic disc herniations is largely unknown, but according to the literature they may be linked
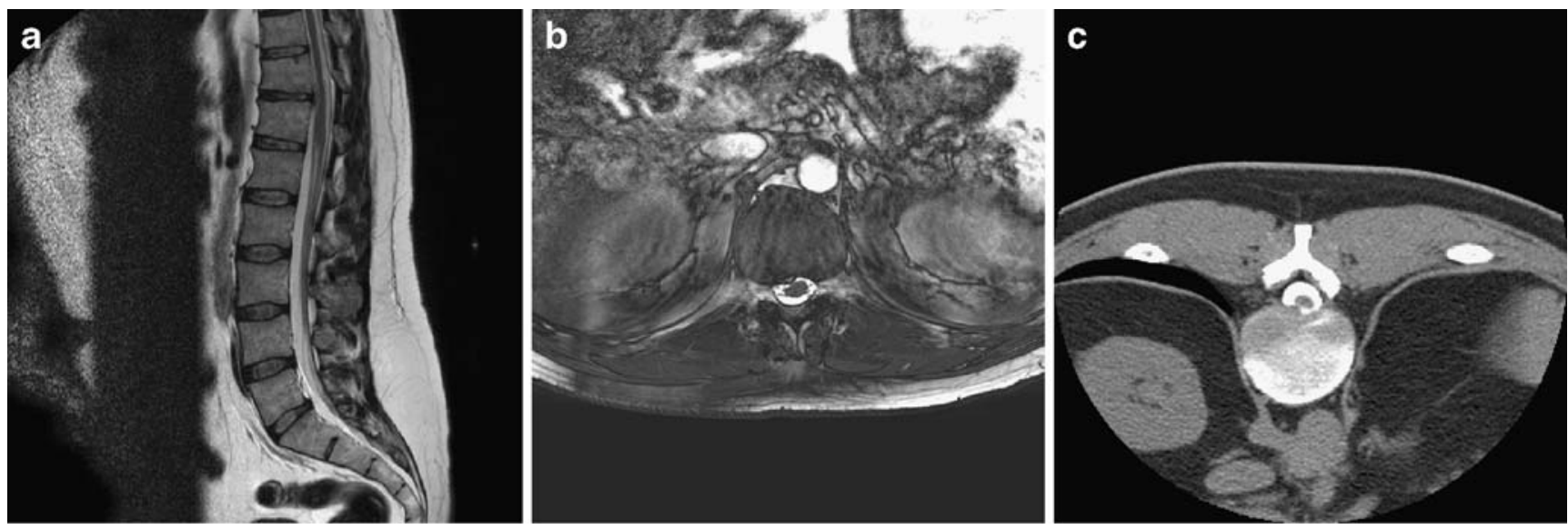

Fig. 1 a-c Patient 1: preoperative sagittal and axial T2-weighted MR images (a and $\mathbf{b}$ ) demonstrating a right mediolateral disc herniation at T11-T12. Note cord deformation (right anterolateral flattening) although there is only a small area of contact between disc herniation and cord. Obliteration of the subarachnoid space is more obvious on the axial $\mathrm{CT}$ image with intrathecal contrast obtained in prone position (c). $C T$ computerized tomography, $M R$ magnetic resonance, $T$ thoracic 
Fig. 2 a (1 and 2), b, c Patient 2: preoperative sagittal T2-weighted and axial T2 DRIVE MR images (a and b) demonstrating a left mediolateral disc herniation at T11-T12 with severe compression of the segmental spinal cord and complete cerebrospinal fluid block. Myelomalacia at this level was recognised by comparison with images at adjacent levels with uncompressed spinal cord (images not shown). The cerebrospinal fluid block at the involved level is clearly visible on a coronal MR myelographic image (c). $M R$ magnetic resonance, $T$ thoracic
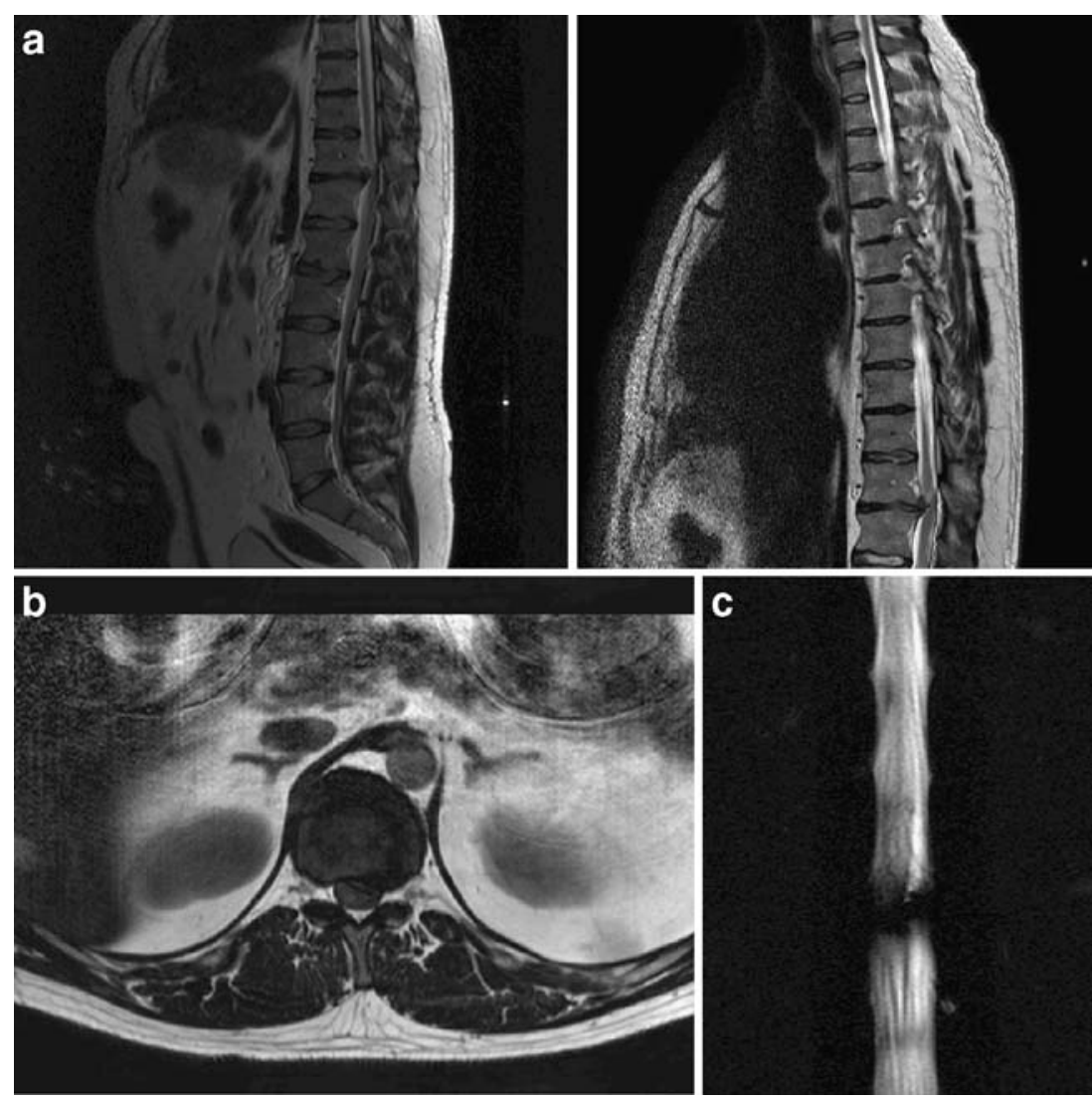

to trauma [9], Scheuermann's disease [6, 15] or a degenerative back [10]. The young age of these brothers, both in their early thirties, and the similarity of their disc herniation, suggest a familial predisposition. On the other hand, the first patient shows evidence of Scheuermann's disease, and therefore his disc herniation may have been related to this, whereas the second did not. A genetic factor has been implicated in the etiopathogenesis of cervical and lumbar disc degeneration $[12,13,18]$ as well as thoracic disc degeneration [16]. Such disc degeneration may result in a tear of the annulus fibrosus and an extrusion of the nucleus pulposus into the spinal canal, thus producing a disc herniation [10]. Moreover, a genetic factor has recently been implicated in the etiology of Scheuermann's disease [4], which has a strong association with thoracic disc herniation according to Gille et al. [6] as well as in our own experience $(58 \%$ of patients with a symptomatic thoracic disc herniation in our series had Scheuermann's disease, unpublished data). This association as well as the observation that thoracic disc herniations can be very large, calcified (even in young patients) and often multiple suggests they may be more related to a growth disturbance early in life, rather than to disc degeneration later in life. Moreover, they are often accompanied by the so-called nuclear trial sign which suggests a migratory path at the level of the intervertebral disc or endplate and may be another finding consistent with a growth disturbance [1]. On the other hand, some thoracic disc herniations have been shown to appear de novo as well [20].

Biochemical differences in the composition of a disc might explain a familial predisposition to disc degeneration in general [13]. Other genetically influenced factors may be body habitus and physical characteristics [13], whereas non-genetically influenced and therefore confounding risk factors in this clinical report may be smoking [8] (patient 1) and performing a physically demanding job [2] (patient 1 and 2), as these are risk factors at least in lumbar disc herniation. Finally, we cannot exclude the possibility that the occurrence of a symptomatic thoracic disc herniation at the exact same level and early age in these brothers was merely coincidental, given the high prevalence $(37 \%)$ of thoracic disc herniations in asymptomatic individuals [21]. In order to answer these questions further research on the etiopathogenesis of thoracic disc herniations, including genetic studies, needs to be done.

\section{Conclusions}

The etiology of thoracic disc herniations is likely multifactorial, and may include such factors as degenerative disc disease, Scheuermann's disease, growth disturbance, trau- 
ma, physically demanding jobs, smoking, as well as a genetic component. Although the occurrence of a symptomatic thoracic disc herniation in siblings may reflect some genetic predisposition, it may also be merely coincidental, given the high prevalence of thoracic disc herniations in asymptomatic individuals. Further research on the etiopathogenesis of these intriguing lesions, including genetic studies, is warranted.

Open Access This article is distributed under the terms of the Creative Commons Attribution Noncommercial License which permits any noncommercial use, distribution, and reproduction in any medium, provided the original author(s) and source are credited.

\section{References}

1. Awwad EE, Martin DS, Smith KR Jr (1992) The nuclear trial sign in thoracic herniated disks. AJNR Am J Neuroradiol 13:137-143

2. Bigos SJ, Battie MC, Spengler DM, Fisher LD, Fordyce WE, Hansson T, Nechemson AL, Zeh J (1992) A longitudinal, prospective study of industrial back injury reporting. Clin Orthop Relat Res 279:21-34

3. Cornips E, Beuls E, Geskes G, Janssens M, van Aalst J, Hofman P (2007) Preoperative localization of herniated thoracic discs using myelo-CT guided transpleural puncture: technical note. Childs Nerv Syst 23:21-26

4. Damborg F, Engell V, Andersen M, Kyvik KO, Thomsen K (2006) Prevalence, concordance, and heritability of Scheuermann kyphosis based on a study of twins. J Bone Joint Surg Am 88:2133-2136. doi:10.2106/JBJS.E.01302

5. Eleraky MA, Apostolides PJ, Dickman CA, Sonntag VK (1998) Herniated thoracic discs mimic cardiac disease: three case reports. Acta Neurochir (Wien) 140:643-646. doi:10.1007/s007010050156

6. Gille O, Soderlund C, Razafimahandri HJ, Mangione P, Vital JM (2006) Analysis of hard thoracic herniated discs: review of 18 cases operated by thoracoscopy. Eur Spine J 15:537-542. doi:10.1007/s00586-005-1014-3

7. Hidalgo Ovejero AM (1999) Thoracic disc herniation mimicking acute lumbar disease. Spine 24:2066-2067. doi:10.1097/ 00007632-199910010-00019

8. Kelsey JL, Githens PB, O'Conner T, Weil U, Calogero JA, Holford TR, White AA 3rd, Walter SD, Ostfeld AM, Southwick WO (1984) Acute prolapsed lumbar intervertebral disc. An epidemiologic study with special reference to driving automobiles and cigarette smoking. Spine 9:608-613. doi:10.1097/00007632198409000-00012

9. Lyu R, Chang H, Tang L, Chen S (1999) Thoracic disc herniation mimicking acute lumbar disc disease. Spine 15:416-418. doi:10.1097/00007632-199902150-00025

10. McInerney J, Ball PA (2000) The pathophysiology of thoracic disc disease. Neurosurg Focus 9(4):e1. doi:10.3171/foc.2000. 9.4 .2

11. Rohde RS, Kang JD (2004) Thoracic disc herniation presenting with chronic nausea and abdominal pain. A case report. J Bone Joint Surg Am 86-A:379-381

12. Sambrook PN, MacGregor AJ, Spector TD (1999) Genetic influences on cervical and lumbar disc degeneration: a magnetic resonance imaging study in twins. Arthritis Rheum 42:366-372. doi:10.1002/ 1529-0131(199902)42:2<366::AID-ANR20>3.0.CO;2-6

13. Simmons ED Jr, Guntupalli M, Kowalski JM, Braun F, Seidel T (1996) Familial predisposition for degenerative disc disease. A case-control study. Spine 21:1527-1529. doi:10.1097/00007632199607010-00007

14. Takeuchi A, Miyamoto K, Hosoe H, Shimizu K (2004) Thoracic paraplegia due to missed thoracic compressive lesions after lumbar spinal decompression surgery. Report of three cases. J Neurosurg 100:71-74

15. Van Landingham JH (1954) Herniation of thoracic intervertebral discs with spinal cord compression in kyphosis dorsalis juvenilis (Scheuermann's disease); case report. J Neurosurg 11:327-329

16. Videman T, Leppavuori J, Kaprio J, Battie MC, Gibbons LE, Peltonen L, Koskenvuo M (1998) Intragenic polymorphisms of the vitamin $\mathrm{D}$ receptor gene associated with intervertebral disc degeneration. Spine 23:2477-2485. doi:10.1097/00007632199812010-00002

17. Vollmer DG, Simmons NE (2000) Transthoracic approaches to thoracic disc herniations. Neurosurg Focus 9(4):e8. doi:10.3171/ foc.2000.9.4.8

18. Waddell G (2004) The back pain revolution, ed 2. Churchill Livingstone, pp 94-95

19. Winter SC, Maartens NF, Anslow P, Teddy PJ (2002) Spontaneous intracranial hypotension due to thoracic disc herniation. Case report. J Neurosurg 96:343-345

20. Wood KB, Blair JM, Aepple DM, Schendel MJ, Garvey TA, Gundry CR, Heithoff KB (1997) The natural history of asymptomatic thoracic disc herniations. Spine 22:525-529, discussion 529-530. doi:10.1097/00007632-199703010-00011

21. Wood KB, Garvey TA, Gundry C, Heithoff KB (1995) Magnetic resonance imaging of the thoracic spine. Evaluation of asymptomatic individuals. J Bone Joint Surg Am 77:1631-1638 